\title{
Virtual Interprofessional Education (VIPE): a Multi-institutional Innovation
}

\author{
Mary Showstark $^{1}\left(\mathbb{0} \cdot\right.$ Dawn Joosten-Hagye $^{2} \cdot$ Andrew C. Wiss $^{3}$
}

Accepted: 3 November 2021 / Published online: 24 November 2021

This is a U.S. government work and not under copyright protection in the U.S.; foreign copyright protection may apply 2021

\begin{abstract}
The virtual interprofessional (VIPE) site provides asynchronous content with both video and written case vignettes, pedagogic facilitator guides, and synchronous scheduling options for IPE trainings. VIPE offers an efficient opportunity for educators and students to learn from, with, and about each other in the virtual world.
\end{abstract}

Keywords Interprofessional education · Asynchronous and synchronous interprofessional learning

Students from "two or more professions" located across the USA and globally have an ongoing need to engage in interprofessional education (IPE) activities that allow them to "learn about, from and with each other" [1]. The original VIPE content was developed to provide access to virtual IPE and multiple professions through a multi-university collaboration among the following universities/professions: Yale Physician Assistant Online, George Washington University Milken Institute School of Public Health, New York University (NYU) Communicative Sciences and Disorders and Occupational Therapy, University of Southern California (USC) Doctor of Physical Therapy, and Master's in Social Work, and Georgetown Nursing.

The VIPE site contains asynchronous content to enhance students understanding of the various health and healthrelated professions (i.e., physician assistant, public health, speech and language pathology, occupational therapy, physical therapy, social work, nursing), video interviews with professionals, and several case studies, including a COVID-19 case. Multi-institutional IPE programs in the USA have often relied on online tools to support their IPE experiences. For example, one systematic review concluded that most occur

Mary Showstark

mary.showstark@yale.edu

1 School of Medicine Physician Assistant Online Program, Yale University, New Haven, CT, USA

2 Dworak-Peck School of Social Work, USC Suzanne, Los Angeles, CA, USA

3 GW Milken Institute School of Public Health, Washington, DC, USA in the form of fully asynchronous work or discussion boards and do not tend to combine both asynchronous content and synchronous meetings in person [2]. Challenges to creating a VIPE lie in administrative support, technical development and support, business operations, planning, and partnerships. This is a partial but not exhaustive list of potential barriers for others to consider when creating such an IPE experience or comprehensive program website.

Facilitators and students must request access for the full VIPE website. Facilitators can select a case and utilize the website's built-in scheduling system to have their students sign up for the IPE asynchronous and synchronous IPE case activity. The facilitator utilizes their own synchronous platform (i.e., Zoom, WebEx, Collaborate Ultra) and provides a link to their virtual meeting room for the students to enter. Previous VIPE experiences have accommodated up to 500 online participants. This large population of participants then breaks out into smaller groups of 10-15 students, with an even distribution of the participating professions in each group, and these groups then engage in problembased learning (PBL) facilitated by a faculty member. This group size falls within known standards for PBL group size and in practice allows for one or more students from each participating discipline to contribute substantively to each PBL small group [3]. To date we have hosted 3 annual multiinstitutional virtual IPEs and, in 2021, began offering virtual IPEs 3 times per academic year.

Throughout the COVID-19 pandemic, VIPE has served as a space where a sense of normalcy regarding IPE has been restored. The VIPE cases and its virtual IPE model have brought healthcare providers and students from around 
the world together, providing opportunities for connections across professions and opportunities to learn from, with and about each other.

Funding This work receives a Josiah Macy Foundation Grant.

\section{Declarations}

Ethical Approval Yale University 2000024050.

Informed Consent NA

\section{References}

1. World Health Organization. Framework for action on interprofessional education and collaborative practice. World Health
Organ. 2010. Available at: https://www.who.int/publications/i/ item/framework-for-action-on-interprofessional-educationcollaborative-practice.

2. West C, Graham L, Palmer RT, Miller MF, Thayer EK, Stuber ML, Awdishu L, Umoren RA, Wamsley MA, Nelson EA, Joo PA, Tysinger JW, George P, Carney PA. Implementation of interprofessional education (IPE) in 16 U.S. medical schools: common practices, barriers and facilitators. J Interprofessional Educ Pract. 2016;4:41-9. https://doi.org/10.1016/j.xjep.2016.05.002.

3. Speck BW. Fostering collaboration among students in problembased learning. New Dir Teach Learn. 2003;2003(95):59. https:// doi.org/10.1002/tl.114.

Publisher's Note Springer Nature remains neutral with regard to jurisdictional claims in published maps and institutional affiliations. 